\title{
Difference in cytokine production and cell cycle progression induced by Epstein-Barr virus Lmp1 deletion variants in Kmh2, a Hodgkin lymphoma cell line
}

Charlotte Sueur ${ }^{1,2,3,4,7^{*}}$, Julien Lupo ${ }^{1,2,3,4}$, Philippe Mas ${ }^{3,5}$, Patrice Morand ${ }^{1,2,3,4}$ and Véronique Boyer ${ }^{1,2,3,6}$

\begin{abstract}
Background: Epstein-Barr virus (EBV) is associated with 20-40\% of Hodgkin's Lymphoma (HL) cases. EBV-encoded latent membrane protein 1 (LMP1) is a well-known oncogenic protein and two C-terminal deletion variants, del30-LMP1 and del69-LMP1, have been described in animal models to be more tumorigenic than the wild-type form. This work aims to detail the implication of LMP1 in the development of HL and to characterize the particular effects of these variants.
\end{abstract}

Methods: We established HL-derived cell lines stably transfected with the PRT-LMP1 vector coding for the EBNA1 gene and allowing expression of the different LMP1 variants under the control of a doxycyclin-inducible promoter. Communication between cells was assessed by measuring the expression of various pro-inflammatory cytokines by flow cytometry after intracellular LMP1 and cytokine double staining. Proliferative properties of LMP1 variants were also compared by studying the repartition of cells in the different phases of the cell cycle after EdU incorporation combined to LMP1 and DAPI staining.

Results: All LMP1 proteins induced the expression of several pro-inflammatory cytokines such as TNF- $a$, TNF- $\beta$, IL-6, RANTES/CCL5 and IFN- $\gamma$. However, the del30-LMP1 variant induced cytokine expression at a lower level than the other variants, especially IFN- $\gamma$, while the del69-LMP1 variant stimulated greater cytokine expression. In addition, we measured that all LMP1 proteins greatly impacted the cell cycle progression, triggering a reduction in the number of cells in S-phase and an accumulation of cells in the G2/M phase compared to the HL-non induced cells. Interestingly, the del30-LMP1 variant reduced the number of cells in S-phase in a significantly greater manner and also increased the number of cells in the G0/G1 phase of the cell cycle.

Conclusion: Weak IFN-y expression and specific alteration of the cell cycle might be a way for del30-LMP1 infected cells to escape the immune anti-viral response and to promote the development of cancer. The differences observed between the LMP1 variants reflect their own oncogenic properties and eventually impact the development of $\mathrm{HL}$.

Keywords: EBV, LMP1, Variant, Hodgkin's Lymphoma, Cytokine, Cell cycle

\footnotetext{
* Correspondence: sueur@unistra.fr

'Université Grenoble Alpes, UVHCl, F-38000 Grenoble, France

${ }^{2} \mathrm{CNRS}, \mathrm{UVHCl}, \mathrm{F}-38000$ Grenoble, France

Full list of author information is available at the end of the article
} 


\section{Introduction}

EBV is an ubiquitous tumor-causing virus infecting more than $90 \%$ of human adults worldwide with a life-long infection in B lymphocytes asymptomatically [1]. EBV infection in HRS cells presents a type II latency program, characterized by the expression of the latent membrane protein 1 (LMP1) and two other viral proteins, EBNA1 and LMP2 in addition to small RNAs, termed EBER 1 and 2 [2]. LMP1 is a multifunctional oncoprotein essential for EBV-induced B-cell proliferation and transformation in vitro [3], as it shares several features with CD40, a member of the tumor necrosis factor receptor family (TNFR). LMP1 activates the transcription factor nuclear factor- $k B(N F-k B)$ by promoting turnover of $I \kappa B \alpha$, an important inhibitor of NF- $\mathrm{kB}$, conferring the cells a protection against apoptosis. A direct link between LMP1 and cell cycle progression has also been shown in several studies although they were essentially focused on NPC cells or Burkitt lymphoma cell lines [4-7].

In the EBV-associated pathologies, different variants of LMP1 have been described. For example, a 30-bp deletion variant at the $\mathrm{C}$ terminal and corresponding to the CAO variant isolated from a NPC patient, was found to have increased potential to transform rodent fibroblasts and to induce tumors in nude mice when compared to wild-type LMP1 [8]. A 69-bp deletion LMP1 variant has also been described in NPC [9] and other lymphoproliferative disorders such as HL [10]. These deletions do not interfere with the stimulation of NF- $\mathrm{BB}[11]$. However, the presence of such variants associated to the pathogenesis of several diseases leads to the hypothesis that polymorphisms within LMP1 gene might influence the susceptibility to develop EBV-associated tumors.

Hodgkin Lymphoma (HL) is a B cell lymphoma, characterized by a minority of neoplastic cells, the Hodgkin and Reed-Sternberg cells (HRS cells), and an extensive inflammatory background. Classical HRS cells derive from postgerminal center B cells, destined for apoptosis in the B cell selection process because of the lack of successful immunoglobulin gene rearrangement. In Western world, $20-40 \%$ of HL are associated with Epstein-Barr Virus (EBV) while in developing countries it reaches 70\% [12]. Interestingly, EBV has been detected in $80-100 \%$ of $\mathrm{HL}$ arising in HIV patients, supporting the notion that this virus plays a pivotal role in the pathogenesis of this tumor [13]. Moreover, presence of the 30-bp deletion in LMP1 has been frequently associated with the HL disease in HIV infected individuals [13,14]. Recently, LMP1 has been shown to increase the DDR1 tyrosine kinase receptor in germinal center B cells, activating the expression of proinflammatory mediators and protecting lymphoma cells from cell death [15]. Besides, many studies have documented that HL is associated with disturbed cytokine production [16]. Cytokine and chemokine production may not only promote growth of HRS cells and help to evade immune surveillance, but they also cause the characteristic histology and the clinical symptoms of HL [17]. Cross-talk between HRS cells and surrounding lymphocytes has been studied for many years, and this interaction appeared to play an important role for the pathogenesis of HL [18]. Few studies have documented the impact of EBV infection on HL development. HL frozen tissues [19] or derived cell lines infected by EBV in vitro or transiently transfected by a constitutive expressed LMP1 vector were used [20-24]. However, results obtained from these studies were difficult to interpret since either there were not quantitative or the cell lines did not express LMP1 until a membrane signal was applied (CD40 ligand and IL4), leading to morphological studies where LMP1 was linked to the formation of multinuclear cells or showing differentially expressed proteins by microarray RNA assays, not confirmed by protein expression techniques. Other studies about LMP1 genetic diversity from samples derived from HL patients focusing mainly on LMP1 variant origin and activation of the NF- $\mathrm{BB}$ pathway were also conducted [25-27]. However, the impact of the LMP1 polymorphism on the HL cells has not been documented.

In this study, we investigated whether WT-LMP1 and the deletion variants del30-LMP1 and del69-LMP1 could modulate cytokine expression and cell cycle progression in $\mathrm{KMH} 2$ - a HL derived cell line - to analyze the impact of LMP1 polymorphism on the development of HL.

\section{Results}

\section{Characterization of the KMH2-pRT-LMP1 established cell} lines

In order to study the impact of different LMP1 deletion variants on the behavior of the KMH2 HL cell line, we established three cell lines stably transfected with the pRT-LMP1 vector coding for either the wild-type form of LMP1 (WT-LMP1) or deleted variants (del30-LMP1; del69-LMP1) (Figure 1a). After electroporation and three weeks of hygromycin selection, presence of the plasmid and expression of viral genes were assessed by inducing cells with doxycyclin for $24 \mathrm{~h}$. Expectedly, RT-PCR showed that the EBNA1 gene was constitutively expressed in the three KMH2-pRT-LMP1 cell lines but not in the KMH2 cells. LMP1 was only expressed in presence of doxycyclin, as shown by RT-PCR (Figure 1b). A shift can be observed between the three PCR products of the LMP1 amplification corresponding to the 30-bp and 69-bp deletions in the LMP1 gene. LMP1 inducible-expression was also observed by western-blotting (Figure 1c) showing no significant difference in LMP1 expression normalized to actin $($ actin/LMP1 ratio: WT-LMP1 ×1.89; del30-LMP1 $\times$ 1.54; del69-LMP1 $\times 1.75$ ). The precise number of cells expressing LMP1 in the three cell lines was determined by flow-cytometry (Figure 1d). On average, 25\% of the 
(a)

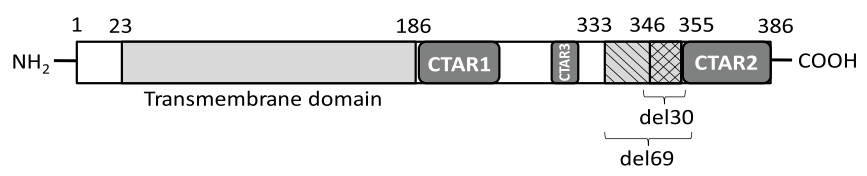

(b)
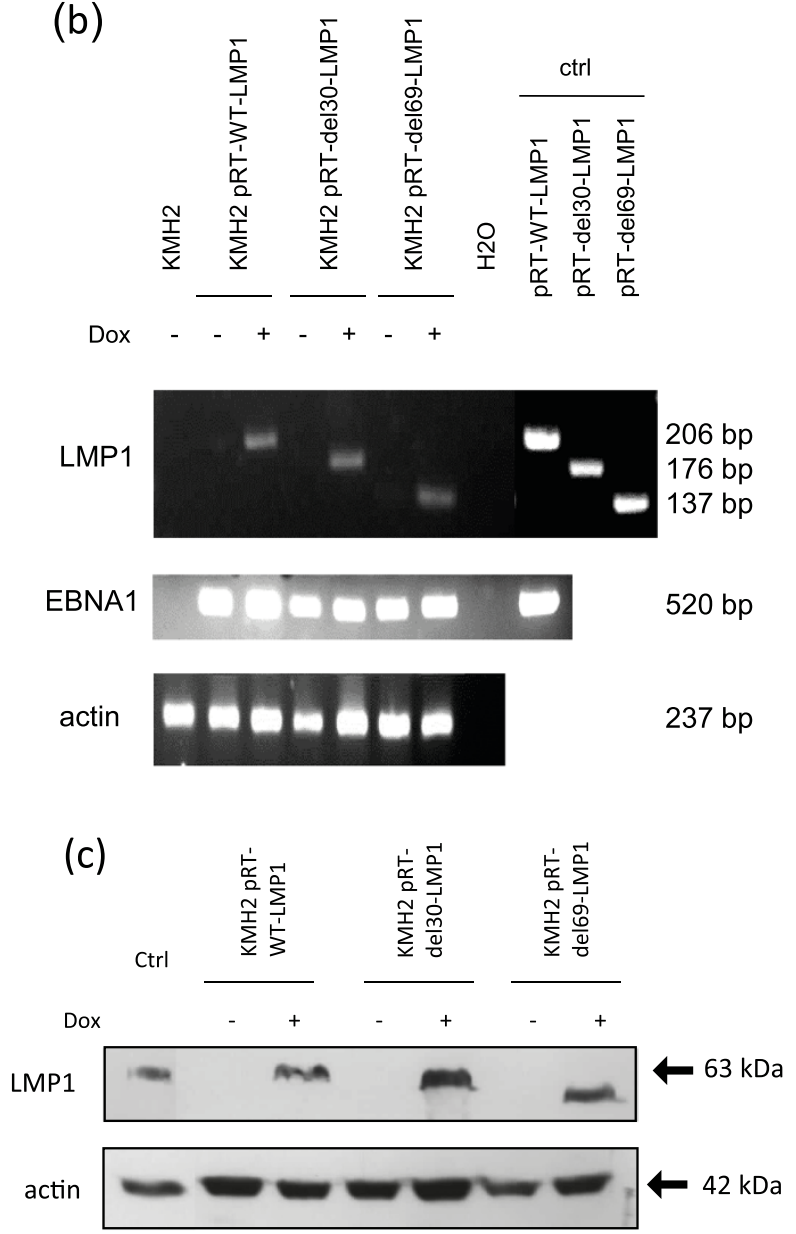

(d)

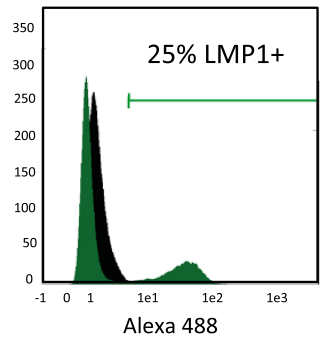

KMH2 pRT-WT-LMP1

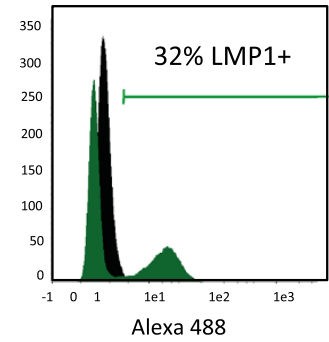

KMH2 pRT-del30-LMP1

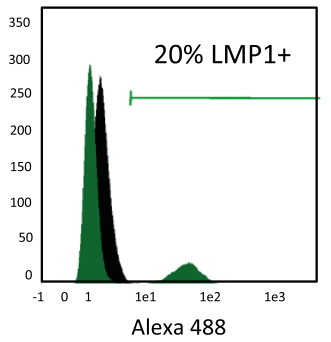

KMH2 pRT-del69-LMP1

Figure 1 Characterization of the KMH2-pRT-LMP1 established cell lines. (a) Linear representation of WT-LMP1 and the 10 and 23 amino-acid deletions corresponding to the del30 and del69-LMP1 variants. (b) RT-PCR or (c) Western blot of EBNA1 and LMP1 in non-induced cells and in doxycyclin-induced cells expressing WT-LMP1, del30-LMP1 and del69-LMP1 variants. 293-HEK cells transiently transfected with PCDNA-WT-LMP1 were used as positive control for immunoblotting. (d) Comparison of LMP1 expression by flow-cytometry in the KMH2-pRT-LMP1 cells. Doxycyclin-induced cells are represented in green and non-induced cells in black. Data are representative of 3 experiments. 
KMH2-pRT-WT-LMP1 cells, 32\% of the KMH2-pRTdel30-LMP1 cells and 20\% of the KMH2-pRT-del69LMP1 expressed LMP1 compared to non-induced cells. These low rates of cells expressing LMP1 could be due to heterogeneity in the LMP1 expression level or to the presence of hygromycin resistant KMH2 cells. Attempts to enrich or clone LMP1 expressing cells (by selecting NGFR-expressing cells or subcloning) were unsuccessful since KMH2 cells express low level of endogenous NGFR and did not grow at low density. In order to study the impact of LMP1 variants on HL cells, we used flow cytometry to gate selectively the LMP1 positive cells among the established cell lines in all the next experiments.

\section{LMP1 induces expression of several cytokines in $\mathrm{KMH} 2$ cells}

Communication between HRS cells and the surrounding immune cells plays a major role in the development of HL. To examine the influence of LMP1 on HRS cytokine secretion, we studied intracellular cytokine expression by flow cytometry in KMH2 cells expressing LMP1 or stimulated by phorbol-myristate-acetate and ionomycin (PMA-iono) as positive control. We choose to study different cytokines involved in inflammatory processes, recruitment of immune cells and HL pathogenesis. After $24 \mathrm{~h}$ of doxycyclin induction, all KMH2-pRT-LMP1 cells expressed TNF- $\alpha$, TNF- $\beta$, IL-6, RANTES/CCL5 and IFN- $\gamma$ (Table 1). On the contrary, none of the LMP1 variants induced expression of TGF- $\beta$, IL-8, IL-9, IL- $1 \alpha$ and IL-1RA, while stimulation of $\mathrm{KMH} 2$ with PMA-ionomycin induced all these cytokines (Table 1). Of note that production of cytokines was not modified by addition of doxycyclin in the non-transfected KMH2 (data not shown). Thus, LMP1 induced the expression of several cytokines in HL cells, promoting the establishment of an inflammatory microenvironment in favor of the tumor development.
del30-LMP1 induces cytokine expression at a lower level than the other LMP1 variants

Furthermore, we investigated the effect of the different LMP1 deletion variants on HRS cytokine secretion. LMP1 and cytokine labeling dot plots are shown in Additional file 1 . IFN- $\gamma$ was significantly induced by WT-LMP1 (21.5 $\pm 5.8 \%)$ and del69-LMP1 $(27.2 \pm 3.4 \%)$ compared to LMP1 non-expressing cells $(3.5 \pm 3.3 \%)$ (Figure $2 \mathrm{a})$. Interestingly, del30-LMP1 increased the number of IFN- $\gamma$ producing cells to a significantly lesser extent $(7.1 \pm 3.4 \%)$ compared to the WT-LMP1 and del69-LMP1 forms, although to a significant amount compared to the non-induced cells. Likewise, the three LMP1 variants were able to induce IL-6 expression compared to non-induced cells $(1.1 \pm$ $1.0 \%$; Figure 2b). However, the number of del30-LMP1 cells was significantly lower $(30.5 \pm 6.9 \%)$ than the two other variants WT-LMP1 $(41.9 \pm 6.9 \%)$ and del69-LMP1 (57.4 $\pm 12.9 \%)$. In addition, a significant greater number of del69-LMP1 cells expressed IL-6 compared with the other variants (Figure $2 \mathrm{~b}$ ). The same observation can be made with RANTES/CCL5, whose expression is induced by all LMP1 variants compared to non-induced cells, and in a significantly higher proportion with the del69-LMP1 variant (control cells $11.7 \pm 3.4 \%$, WT-LMP1 $34.0 \pm$ 3.8\%, del30-LMP1 27.7 $\pm 5.5 \%$, del69-LMP1 46.2 $\pm 6.3 \%$ ) (Figure 2c). Two members of the TNF family were then analyzed. TNF- $\beta$ expression was induced by all LMP1 variants compared to $\mathrm{KMH} 2$ control cells $(13.4 \pm 5.4 \%)$ with a significantly smaller percentage of del30-LMP1 cells expressing TNF- $\beta(52.0 \pm 4.0 \%)$ in relation to the two other variants WT-LMP1 $(62.3 \pm 6.4 \%)$ and del69-LMP1 $(71.7 \pm 5.6 \%)$ (Figure $2 \mathrm{~d}$ ). TNF- $\alpha$ expression was induced by LMP1 compared to non-induced $\mathrm{KMH} 2$ cells $(3.0 \pm$ $1.6 \%$; Figure 2e). No significant difference could be observed between the LMP1 variants (WT-LMP1 21,7 \pm 2.4\%; del30-LMP1 24,9 \$ 4.4\%; del69-LMP1 $21.1 \pm 0.6 \%$ ).

Table 1 Cytokine expression induced in Hodgkin's lymphoma-derived cells

\begin{tabular}{|c|c|c|c|c|}
\hline & KMH2 PMA-iono & KMH2 pRT-WT-LMP1 & KMH2pRT-del30-LMP1 & KMH2 pRT-del69-LMP1 \\
\hline TNF-a & + & + & + & + \\
\hline TNF- $\beta$ & + & + & + & + \\
\hline IL-6 & + & + & + & + \\
\hline RANTES/CCL5 & + & + & + & + \\
\hline IFN- $\gamma$ & + & + & + & + \\
\hline TGF- $\beta$ & + & - & - & - \\
\hline $\mid \mathrm{L}-8$ & + & - & - & - \\
\hline IL-9 & + & - & - & - \\
\hline IL-1a & + & - & - & - \\
\hline IL-1RA & + & - & - & - \\
\hline
\end{tabular}

Cytokine expression was assessed by flow cytometry analysis after induction of KMH2 cells with PMA-ionomycin or doxycyclin for $24 \mathrm{~h}$. 

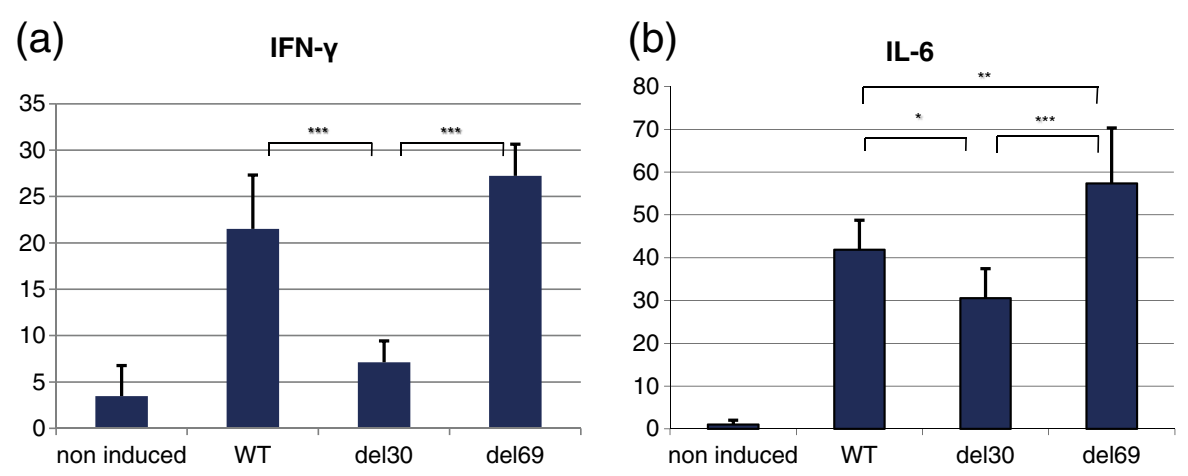

(c)
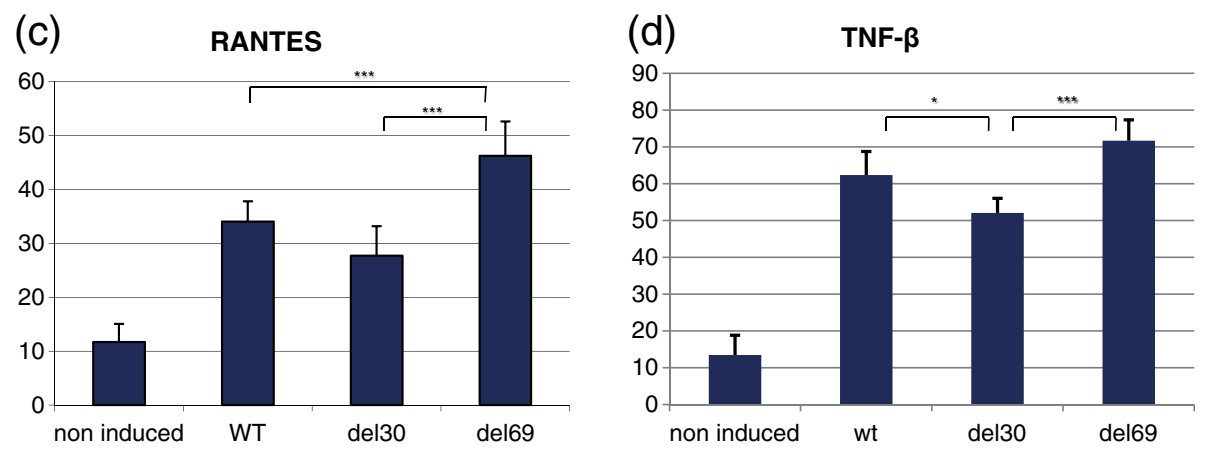

(e)

TNF- $\alpha$

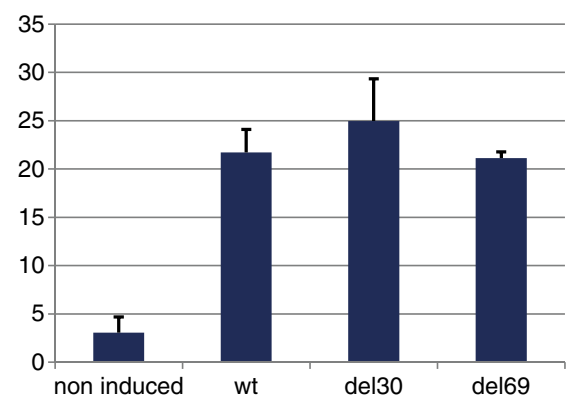

Figure 2 Cytokine expression is differently regulated by LMP1 variants. Cytokines expressed by KMH2-pRT-LMP1 cells (non-induced, WT, del30 and del69) were intracellularly stained and detected by flow-cytometry $24 \mathrm{~h}$ after induction of LMP1 expression. The percentages of cells expressing (a) IFN- - , (b) IL-6, (c) RANTES/CCL5, (d) TNF- $\beta$ and (e) TNF-a were compared. All cytokines were significantly more expressed in LMP1 expressing cells compared to non-induced cells with an ANOVA analysis (of note that expression of IFN- $\gamma$ was significantly higher in KMH2-pRT-del30-LMP1 cells compared to the control unstimulated KMH2 cells with an ANOVA analysis followed by a Dunnett post-test). Supplemental data showing LMP1 and cytokine labeling dot plots are provided as Additional file 1.

To sum up, del30-LMP1 tended to induce cytokine expression at a lower level compared with both forms: WT-LMP1 and del69-LMP1. Nonetheless, del69-LMP1 seemed to induce more cytokine expression than the two other LMP1 variants.

LMP1 variants influence differently cell cycle progression The LMP1 deletion variants have been shown to be more tumorigenic than the WT-LMP1 $[8,28]$. In order to study the effect of LMP1 variants on the cell cycle progression in the $\mathrm{KMH} 2$ cell line, percentages of cells in the different phases of cell cycle were determined by flow cytometry, using DAPI and EdU incorporation as shown in Figure 3a. Twenty four hours after induction, all LMP1-expressing cells show a significantly smaller percentage of cells in $S$ phase than the control cells (Figure 3b). We verified that the observed effects were actually due to the expression of LMP1 rather than the presence of doxycyclin in the medium by inducing nontransfected $\mathrm{KMH} 2$ cells with doxycyclin for $24 \mathrm{~h}$. Indeed, no difference could be detected between doxycyclininduced and non-induced $\mathrm{KMH} 2$ cells (data not shown). It is worth noting that the expression of del30-LMP1 variant reduced the percentage of cells in $S$ phase more 

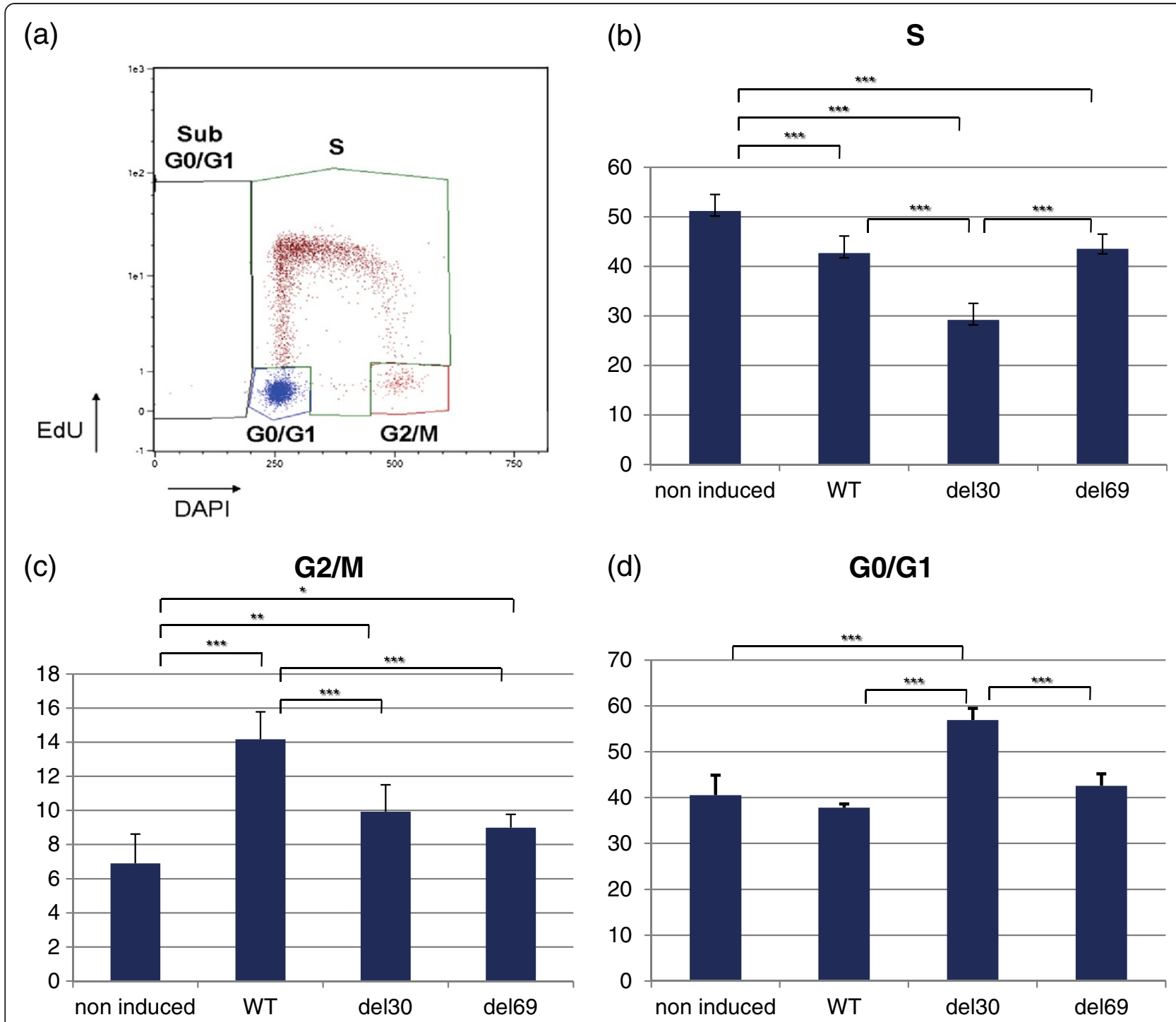

(e)

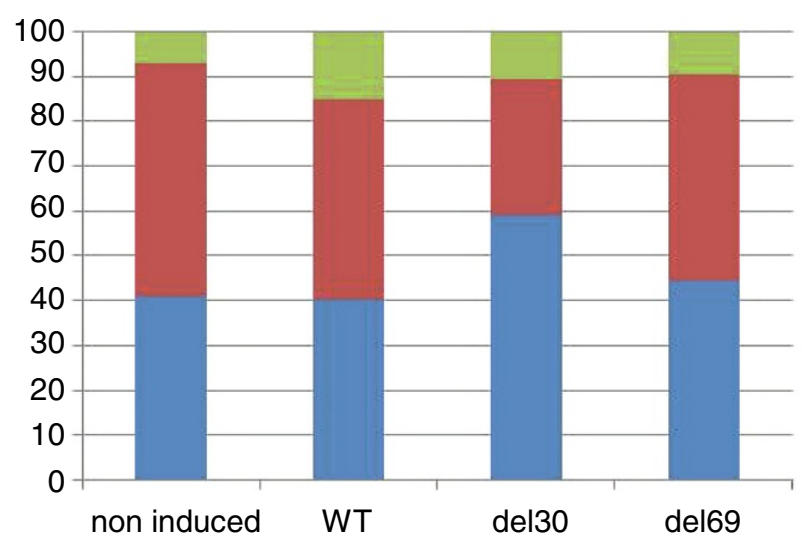

- $\mathrm{G} 2 / \mathrm{M}$

- $S$

- G0/G1

Figure 3 (See legend on next page.) 
(See figure on previous page.)

Figure 3 LMP1 influences cell cycle progression in the KMH2 Hodgkin's lymphoma cell lines. Percentage of cells in the different phases of cell cycle was assessed by measurement of EdU incorporation and DAPI staining by flow cytometry after induction of LMP1 expression in the KMH2-pRT-LMP1 cell lines (non-induced, WT, del30 and del69). (a) Example of cell cycle dot plot, (b) Cells in S phase, (c) Cells in G0/G1 phase and (d) Cells in G2/M phase. (e) Repartition of cells in the different phases of the cell cycle represented in a stacked histogram.

significantly than the two other LMP1 variants (Figure 3b). If all LMP1 variants had an enhanced percentage of cells in $\mathrm{G} 2 / \mathrm{M}$ phase compared to the control cells $(6.9 \pm 1.7 \%)$, WT-LMP1 induced a significantly higher accumulation of cells in G2/M phase $(14.2 \pm 1.6 \%)$ than the deletion variants del30-LMP1 $(9.9 \pm 1.6 \%)$ and del69-LMP1 $(9.0 \pm$ $0.8 \%$ ) (Figure 3c). Interestingly, expression of del30-LMP1 promoted a significant accumulation of cells in G0/G1 phase $(56.9 \pm 2.6 \%)$ compared to the control cells $(40.5 \pm$ $4.4 \%)$ while WT-LMP1 $(37.8 \pm 0,8 \%)$ and del69-LMP1 $(42.6 \pm 2.6 \%)$ did not differ from non-induced cells (Figure 3d). Percentage of sub-G0/G1 cells was slightly increased by the expression of WT-LMP1 $(3.16 \pm 1.76 \%)$ or del69-LMP1 $(2.85 \pm 0.99 \%)$ protein compared to control cells $(1.14 \pm 0.67 \%)$ (data not shown). However, number of del30-LMP1 cells in sub-G0/G1 phase was not significantly different compared with control cells $(2.33 \pm$ $0.54 \%)$.

Thus, all variants reduced the $\mathrm{S}$ phase and accumulated cells in the G2/M phase, suggesting a blockade at the G1/S checkpoint and a block to completion of mitosis in the KMH2 cells (Figure 3e). The del30-LMP1 variant significantly reduced the number of S-phase cells and further increased the G0/G1-phase cells.

\section{Discussion}

In the context of $\mathrm{HL}$, where tumor cells represent only 0.1 to $1 \%$ of the cells surrounded by fibroblasts and immune cells, communication between cells mediated by cytokines and chemokines is of upmost importance. LMP1 is a well-known oncogene involved in many cellular signaling pathways and thus able to interfere in cytokine secretion. Previously, LMP1 has been shown to induce IL-6 and IL-8 secretion in epithelial cells [29] via the NF-kB pathway [30] and IL-10 in Burkitt lymphoma cells [31]. In LCL, LMP1 triggers cell proliferation by inducing cytokines such as CCL3 and CCL4 through the JUN-kinase pathway [32], and also uses the NF- $\mathrm{kB}$ pathway to stimulate IFN secretion [33]. In this study, we showed that LMP1 induced significantly the expression of several cytokines in LMP1 positive KMH2 HL-derived cells, such as IFN- $\gamma$, IL-6, RANTES/CCL5, TNF- $\beta$ and TNF- $\alpha$. These cytokines are mainly pro-inflammatory, attracting immune cells in the microenvironment and known to be implicated in the development of $\mathrm{HL}$ $[17,34]$. Vockerodt et al. [24] showed that LMP1 induced high levels of IL1, IL8 and RANTES mRNAs in primary human tonsillar germinal center B cells (CD10+ cells). We did not find IL8 and IL1 elevated amounts in the LMP1 positive KMH2 cell lines. Whether this discrepancy is due to the different techniques used or to the cells still remains to be determined.

Little is known about the influence of LMP1 on cytokine production in the particular context of HL. An histological study showed that IL-6 was more often expressed in LMP1-positive HRS cells compared to the negative ones [35]. Showing differences in cytokine expression between the three LMP1 positive forms could be of interest to HL. While a significantly higher number of del69-LMP1 cells expressed IL-6 and RANTES, del30-LMP1 cells expressed IFN- $\gamma$, IL- 6 and TNF- $\beta$ in a significantly lesser extent than the other variants. IFN- $\gamma$ is involved in the anti-viral response against EBV-infected cells. Weak IFN- $\gamma$ expression might be a way for del30-LMP1 infected cells to escape the immune anti-viral response. Besides, on the one hand, the presence of cytokines is necessary for cell survival and tumor promotion. Yet, on the other hand, an excessive cytokine secretion stimulates the recognition and degradation of EBV-infected cells by the immune system. The low level of cytokines expressed in del30-LMP1 KMH2 cells could be a mechanism for EBV to promote the development of HL while escaping the immune surveillance. These observations are consistent with the high frequency of del30-LMP1 variant observed among HIV positive people developing a HL $[13,14]$. On the contrary, the high proportion of del69-LMP1 HL cells to express pro-inflammatory cytokines could trigger their recognition by the immune system and would explain the low frequency of the del69-LMP1 variant in vivo, described only sporadically in NPC or some lymphoproliferative diseases. Prognostic significance of pretreatment serum cytokines in HL has been described [36]. In particular, they show that serum levels of IL6 and IL2R may be used to identify patients with HL at risk for early-disease relapse. Since we found that IL6 was less induced by the del30-LMP1 variant, it thus would be of great interest to determine in vivo, if the IL6 level in serum may be linked to the presence of del30-LMP1 variant and of early-disease relapse.

Oncogenic LMP1 has also a great influence on cell proliferation and survival by contributing to cell cycle progression. Here we show for the first time in HL cells, that all LMP1 variants interfered with cell cycle progression. LMP1 caused a decrease in the S-phase cell population, particularly significant with the del30-LMP1 variant and 
an increase of the G2/M-phase cells. The del30-LMP1 variant provoked an additional accumulation of cells in the G0/G1 phase. These observations were consistent with previous studies performed in NPC cell lines and LCLs with WT-LMP1 or a NPC-derived variant, carrying the 30 bp deletion [4,7]. LMP1 has been described to impair G2 checkpoint leading to a possible accumulation of cells with unrepaired DNA damages [4] or to promote cell cycle progression by accelerating the G1/S transition $[5,37]$. On the other hand, LMP1 has also been described to have cytostatic or even cytotoxic effects when expressed at high levels $[7,38]$. A recent work suggests that the ability of LMP1 to exert both cytotoxic and pro-proliferative properties is necessary during the transformation process [39]. While LMP1 induces cell death in the microenvironment, only EBV infected cells expressing the oncogenic LMP1 survive [39]. The fact that LMP1 variants do not elicit the same effect on cell cycle progression suggests that they have different impact on cell cycle checkpoints. This could directly reflect on their oncogenic potential. Besides, cytokines themselves can influence the cell cycle progression. For example, IL-8 is often overexpressed in cancers and contributes to the tumor development by promoting the G1/S transition of cell cycle [40]. It would be interesting to further investigate the cellular mechanism involved in cell cycle progression with each LMP1 variant and particularly the impact of the LMP1-induced cytokines.

In conclusion, this study brings new insights into the impact of LMP1 on cytokine expression and cell cycle progression in HL. We highlight differences between LMP1 variants which could partly be responsible for their respective oncogenic properties and explain their implication as risk factors in the development of HL.

\section{Materials and methods Plasmid constructs}

We performed an overlapping PCR using the p2167 plasmid (kindly provided by W. Hammerschidt, Munich, Germany), in order to create the 30-bp and 69-bp deletions in the BNLF1 gene coding for LMP1 [41]. The p2167 plasmid contains $9.5 \mathrm{~kb}$ of the EBV genome, as described [42]. Two DNA fragments surrounding the deletions (respectively in position 1190-1229 and 11611229) were amplified by PCR with a high fidelity polymerase (Pfu, Promega, Fitschburg, WI, USA). The following primers were used,

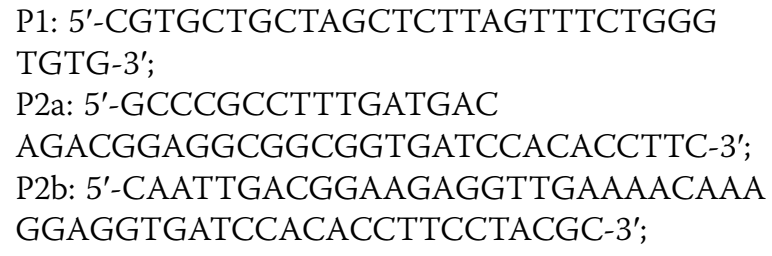

P3a: 5'-TCCGTCTGTCATCAAAGGCGGGC-3'; P3b: 5'-TCCTTTGTTTTCAACCTCTTCCGTC AATTG-3'; P4: 5'-GCCCTTTGTATACTCCTACTGATGAGTA AGTATTACACCC-3'.

First, two PCRs were performed with $50 \mathrm{ng}$ of the p2167 plasmid in a total volume of $50 \mu \mathrm{l}$, with primers $\mathrm{P} 1+\mathrm{P} 2 \mathrm{a}$ and $\mathrm{P} 3 \mathrm{a}+\mathrm{P} 4$ for the 30-bp deletion or P1 + P2b and $\mathrm{P} 3 \mathrm{~b}+\mathrm{P} 4$ for the 69 -bp deletion. After $5 \mathrm{~min}$ of denaturation at $95^{\circ} \mathrm{C}, 10 \mathrm{cycles}$ of $30 \mathrm{sec}$ at $95^{\circ} \mathrm{C}, 30 \mathrm{sec}$ at $55^{\circ} \mathrm{C}$ and 2 min at $72^{\circ} \mathrm{C}$ were carried out, followed by an elongation step for $5 \mathrm{~min}$ at $72^{\circ} \mathrm{C}$. PCR products were purified by QIAEX purification kit (Qiagen, Hilden, Germany), quantified by the nanodrop system (Labtech, Uckfield, United-Kingdom) and equimolarly mixed to be submitted to a second PCR. After 10 cycles with the same program but without primers, allowing the first two PCR products to hybridize, external primers P1 and P4 were added for another 20 cycles. The final $1.6 \mathrm{~kb}$ PCR product containing the 30-bp or 69-bp deletion was reintroduced into the original p2167 plasmid in the NheI and Bst1107I restriction sites and subcloned into the Sfi-I sites of the pRT-LMP1 vector (kindly provided by J. Feuillard, Limoges, France) with the In-Fusion HD cloning kit (Clontech, Mountain View, CA, USA). This vector includes the EBNA1 and hygromycin $\mathrm{B}$ resistance genes, that favour maintenance of the vector as an episome in the cells, and allow selection of transfected cells respectively. A bidirectional tetracyclin-inducible promoter drives the expression of LMP1 and NGFRt [43]. The pcDNA-WT-LMP1 plasmid is a kind gift from F. Grässer (Hambourg, Germany).

\section{Cell culture, transfection and induction}

293-HEK cells (human embryonic kidney cell line) were cultured in DMEM supplemented with heat inactivated fetal bovine serum 10\% and antibiotics (100 units $/ \mathrm{ml}$ penicillin/streptomycin and $1 \mu \mathrm{g} / \mathrm{ml}$ ofloxacin). KMH2 cells (EBV-negative Hodgkin Lymphoma-derived cell line obtained from DSMZ, Braunschweig, Germany) were cultured in RPMI supplemented with $10 \%$ heat inactivated fetal bovine serum and antibiotics (100 units/ml penicillin/streptomycin, $1 \mu \mathrm{g} / \mathrm{ml}$ ofloxacin), at $37^{\circ} \mathrm{C}$ in a $5 \%$ $\mathrm{CO}_{2}$ atmosphere. For transient transfection of pcDNAWT-LMP1 in 293-HEK cells, $5.10^{5}$ cells were plated in a 35-mm petri dish and transfected with Lipofectamine 2000 (Invitrogen, Carlsbad, CA, USA) in the ratio of $10 \mu \mathrm{l}$ transfection reagent for $4 \mu \mathrm{g}$ of DNA, following the manufacturer's instructions. Establishment of KMH2 cell lines stably transfected with the three pRT-LMP1 plasmids (pRT-WT-LMP1, pRT-del30-LMP1 and pRTdel69-LMP1) was performed with the Amaxa electroporation system (Amaxa, Cologne, Germany), according 
to the manufacturer's instructions. Five millions KMH2 cells were electroporated with $5 \mu \mathrm{g}$ of DNA, using the Nucleofactor kit-T (Amaxa) and the T-001 program. Cells were then resuspended in $5 \mathrm{ml}$ of fresh RPMI with $20 \%$ FBS, supplemented with $1 \mathrm{X}$ non-essential amino-acids, $10 \mathrm{mM}$ Hepes and $1 \mathrm{mM}$ sodium pyruvate. Hygromycin was introduced in the medium $48 \mathrm{~h}$ after the transfection at $200 \mu \mathrm{g} / \mathrm{ml}$. After three weeks of selection, LMP1 expression was assessed by flow cytometry after inducing the cells with $1 \mu \mathrm{g} / \mathrm{ml}$ doxycyclin (Clontech) for $24 \mathrm{~h}$, as described elsewhere [43].

\section{Western-blotting}

Five millions KMH2-pRT-LMP1 cells were grown in presence or not of doxycyclin for $24 \mathrm{~h}$. Cells were lysed in a buffer composed of $50 \mathrm{mM}$ Tris $\mathrm{pH}$ 6.8, 2\% SDS, $10 \%$ glycerol and protease inhibitors. Lysates were sonicated and total proteins were quantified with BCA kit (Pierce, Rockford, IL, USA) according to the manufacturer's instructions. Fifty micrograms of total proteins were separated on a 9\% SDS-PAGE gel, transferred on a PVDF membrane and revealed by western-blot analysis with an anti-LMP1 antibody (monoclonal CS.1-4, Dako, Glostrup, Denmark, 1:100) and a rabbit polyclonal anti-actin (Sigma, St Louis, MO, USA; 1:400). Secondary HRP-conjugated anti-mouse (1:20000), anti-rabbit antibodies (1:10000) were purchased from Invitrogen). The signal was developed by Supersignal West Pico Chemiluminescent Substrate (Pierce). The intensity of protein bands was quantified with Adobe Photophop CS3 software.

\section{RNA extraction and RT-PCR}

Total RNA was extracted from 5.10 $\mathrm{KMH2}$-pRT-LMP1 cells with TRI-Reagent (Euromedex, Souffelweyersheim, France), quantified with a nanodrop ND1000 instrument system (Labtech) and treated with Turbo-DNase (Ambion, Austin, TX, USA). cDNA was synthesized from $1 \mu \mathrm{g}$ total RNA with random hexamers, using the superscript III (Invitrogen) in a total volume of $20 \mu \mathrm{l}$. PCRs were then performed on $1 \mu \mathrm{l}$ of cDNA, with $0.25 \mathrm{U}$ of the Phusion polymerase (Thermo-Scientific, Waltham, MA, USA) in the provided buffer, in presence of $200 \mu \mathrm{M} d N T P$ and $200 \mu \mathrm{M}$ of specific primers. Primer sequences are: LMP1-forward, 5' -CCTCATAGCCCTAGCGACTC-3' ; LMP1-reverse, 5'-GTCGTCATCATCTCCACCGG-3' ; EBNA1-forward, 5' -CCGCAGATGACCCAGGAGAA-3' ; EBNA1-reverse, 5'-TGGAAACCAGGGAGGCAAAT-3' ; $\beta$-actin-forward, 5'-CGTGATGGTGGGCATGGG-3' $\beta$ actin-reverse, $5^{\prime}$-CTGGGTCATCTTCTCGCG-3'. After a denaturation step of $3 \mathrm{~min}$ at $94^{\circ} \mathrm{C}$, the following cycle was applied to the samples : $30 \mathrm{sec}$ at $94^{\circ} \mathrm{C}, 30 \mathrm{sec}$ at $60^{\circ} \mathrm{C}$ (for EBNA1, $\mathrm{T}_{\mathrm{H}}$ was $56^{\circ} \mathrm{C}$ ), $30 \mathrm{sec}$ at $72^{\circ} \mathrm{C}$, repeated 26 times for the actin amplification and 30 times for LMP1 and EBNA1 amplifications. A final elongation step was performed for $5 \mathrm{~min}$ at $72^{\circ} \mathrm{C}$. PCR products were migrated on a $2 \%$ agarose gel in $1 \mathrm{X}$ TAE buffer and visualized with ethidium bromide staining (Invitrogen).

\section{LMP1 staining and intracellular cytokine detection}

$\mathrm{KMH} 2$ cells were either treated by doxycyclin $(1 \mu \mathrm{g} / \mathrm{ml})$ to induce LMP1 expression or stimulated with $50 \mathrm{ng} / \mathrm{ml}$ PMA (Sigma) and $1 \mu \mathrm{g} / \mathrm{ml}$ ionomycin (Sigma) to be used as positive control for cytokine expression during $24 \mathrm{~h}$. Throughout the last $4 \mathrm{~h}$ of doxycyclin or PMA-ionomycin induction, cells were treated with $10 \mu \mathrm{g} / \mathrm{ml}$ brefeldin A (BioLegend, San Diego, CA, USA) and $2 \mu \mathrm{M}$ monensin (Sigma) to block secretion of cytokines. Cells were collected and fixed with fixation buffer (BioLegend) for $20 \mathrm{~min}$ at room temperature. Cells were then permeabilized by two centrifugations (for $8 \mathrm{~min}$ at $350 \mathrm{~g}$ ) with permeabilization wash buffer (BioLegend) allowing sequential double immunolabeling of LMP1 and cytokines of interest. LMP1 staining was performed primarily as follows: cells were saturated for $30 \mathrm{~min}$ in $100 \mu \mathrm{l} \mathrm{RPMI}$ containing 10\% human plasma (kindly provided by EFS Rhône-Alpes, Grenoble, France) and $0.1 \%$ triton $\mathrm{X}-100$, incubated for $30 \mathrm{~min}$ with the antiLMP1 antibody (1:100) and washed twice with $5 \mathrm{ml}$ of RPMI. Cells were then incubated for $30 \mathrm{~min}$ with an Alexa A488 or A594-conjugated anti-mouse antibody (Invitrogen, 1:2500) and washed twice with $5 \mathrm{ml}$ of RPMI. An antimouse secondary antibody free Fab sites was finally satured with a mouse hybridoma supernatant (clone D3210, kindly provided by E. Drouet, UVHCI, Grenoble, France). In a second step, intracellular cytokine staining was carried out by resuspending cells in $100 \mu \mathrm{l}$ of permeabilization wash buffer supplemented with the anti-cytokine antibody and incubated for $20 \mathrm{~min}$ at room temperature, protected from light. Cells were then washed twice with $2 \mathrm{ml}$ of permeabilization wash buffer and finally resuspended in cell staining buffer (BioLegend) for flow cytometry analysis on a MACSQuant VYB (Miltenyi Biotech GmbH, Bergisch Gladbach, Germany). Anti-cytokine antibodies used were APC-conjugated anti-human TNF- $\alpha$ (clone Mab11) or its mouse isotype control (clone MOPC21), PE-conjugated anti-human IL-6 (clone MQ2-13A5), anti-human IL-8 (E8N1), antihuman TNF- $\beta$ (clone 359-81-11), anti-human TGF- $\beta$ (TW4-2 F8), anti-human IL-1 $\alpha$ (364-3B3-14), rat isotype control (clone RTK2071) and mouse isotype control (clone MOPC21) from BioLegend, PE-conjugated anti-human

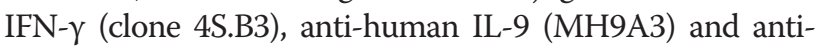
human RANTES/CCL5 (clone 2D5) from BD Pharmingen (San Diego, CA, USA), or FITC-conjugated anti-human IL1-RA (CRM17) and its mouse isotype control (P3.6.2.8.1) from eBioscience (San Diego, CA, USA).

\section{Cell cycle and proliferation}

In order to determine the percentage of cells in the different phases of cell cycle, we used the EdU-click 555 (Jena 
Bioscience, Jena, Germany) combined with LMP1 and DAPI staining. EdU is a nucleoside analogue to thymidine incorporated into DNA, it reveals the proliferating cells in $S$ phase. DAPI measures the total quantity of DNA in the cells and the LMP1 labelling enables to select only the LMP1-expressing cells for our study. Cells were induced with doxycyclin for $24 \mathrm{~h}$ and, during the last $150 \mathrm{~min}$, $10 \mu \mathrm{M}$ EdU was added in the culture medium. Cells were, then, fixed with fixation buffer and permeabilized with permeabilization wash buffer (BioLegend). For EdU revelation, cells were resuspended in the cocktail-click containing TAMRA-azide, incubated for $30 \mathrm{~min}$ at room temperature protected from light and washed twice with $6 \mathrm{ml}$ PBS. LMP1 staining was performed as described previously for intracellular cytokine detection and cells were finally incubated in PBS with $1 \mathrm{~g} / \mathrm{L}$ glucose, DAPI 1:1000 and $100 \mu \mathrm{g} / \mathrm{ml}$ RNAseA until flow cytometry analysis.

\section{Statistical analysis}

Means, standard deviations and p-values were calculated with the GraphPad InStat3 software (San Diego, CA, USA). All bar graphs represent means as per at least three independent experiments for cytokine detection and at least five independent experiments for cell cycle studies. Error bars represent standard deviations. To assess statistical differences, means were compared through a one-way ANOVA test followed by a Tukey post-test for multiple comparison significance test between the analyzed groups. When specified, for single comparison of a population with the control cell group, the ANOVA test was followed by a Dunnett post-test. " stands for $\mathrm{p}<0.05$, ${ }^{* *}$ for $\mathrm{p}<0.01$ and ${ }^{* * * *}$ for $\mathrm{p}<0.001$.

\section{Additional file}

Additional file 1: Cytokine expression by KMH2-pRT-LMP1 expressing cells. Cytometric data plots are presented for each cytokine expressed by the three KMH2-pRT-LMP1 cell lines, with or without induction of LMP1 expression, compared to an isotypic control antibody. X-axis shows LMP1 expression while Y-axis represents cytokine expression. Percentages of cells in each quadrant are given in black. LMP1-positive cells (right upper and lower quadrants) are selectively gated and considered $100 \%$ in order to calculate the percentage of LMP1-positive cells expressing the cytokine of interest, indicated in red. Experiments have been conducted in triplicates and pictures shown here represent only one out of three experiments.

\section{Competing interests}

The authors declare that they have no competing interests.

\section{Authors' contribution}

$C S, J L$ and VB designed the experiments and analyzed the data; $C S, J L$, and PhMa performed the experiments; PM provided critical expertise in the EBV field; CS and VB wrote the manuscript; and all the authors approved the manuscript.

\section{Acknowledgments}

This research was supported by the Agence Nationale de Recherches sur le Sida et les hépatites virales (ANRS-Lymphovir sub-study), Sidaction, the Centre National de Recherche Scientifique (CNRS), the Institut National de la
Santé et de la Recherche Médicale (INSERM), the University Joseph Fourier, the Grenoble University Hospital. We thank Evelyne Manet, Henri Gruffat (ENS-Lyon, France) and Xavier Ronot (FRE AGIM CNRS-UJF 3405, Grenoble, France) for helpful advice and discussions. We thank Rose-Laure Revel-Goyet, Françoise Lacroix and Jean-Philippe Kleman (Institut de Biologie Structurale, Grenoble) for the support and access to the Cell imaging Platform. This work used the platforms of the Grenoble Instruct center (ISBG ; UMS 3518 CNRSCEA-UJF-EMBL) with support from FRISBI (ANR-10-INSB-05-02) and GRAL (ANR-10-LABX-49-01) within the Grenoble Partnership for Structural Biology (PSB). V. B. is an INSERM scientist.

\section{Author details}

${ }^{1}$ Université Grenoble Alpes, UVHCl, F-38000 Grenoble, France. ${ }^{2} \mathrm{CNRS}$, UVHCl, F-38000 Grenoble, France. ${ }^{3}$ Unit for Virus Host-Cell Interactions, Univ. Grenoble Alpes-EMBL-CNRS, 6 rue Jules Horowitz, Grenoble 38042, France. ${ }^{4} \mathrm{CHU}$ de Grenoble, CS 10217, 38043 Grenoble, Cedex 9, France. ${ }^{5}$ EMBL Grenoble Outstation, F-38000 Grenoble, France. ${ }^{6}$ UMR 912 SESSTIM, 23 rue S. Torrents, 13006 Marseille, France. ${ }^{7}$ Hopitaux Universitaires de Strasbourg, Plateau Technique de Microbiologie, Laboratoire de Virologie, 1, place de l'hôpital, BP426 67091 Strasbourg, Cedex, France.

Received: 15 January 2014 Accepted: 8 May 2014

Published: 19 May 2014

\section{References}

1. Rickinson K: Fields Virology. In Epstein-Barr virus. 2nd edition. Edited by Howley PM, Knipe DM, Griffin BD, Lamb RA, Martin MA, Roizman B, Straus SE. Philadelphia: Lippincott Williams et Wilkins; 2007.

2. Young LS, Murray PG: Epstein-Barr virus and oncogenesis: from latent genes to tumours. Oncogene 2003, 22(33):5108-5121.

3. Kaye KM, Izumi KM, Kieff E: Epstein-Barr virus latent membrane protein 1 is essential for B-lymphocyte growth transformation. Proc Natl Acad Sci U S A 1993, 90(19):9150-9154.

4. Deng W, Deng W, Pang PS, Tsang CM, Hau PM, Yip YL, Cheung AL, Tsao SW: Epstein-Barr virus-encoded latent membrane protein 1 impairs G2 checkpoint in human nasopharyngeal epithelial cells through defective Chk1 activation. PLoS One 2012, 7(6):e39095.

5. Lo AK, Huang DP, Lo KW, Chui YL, Li HM, Pang JC, Tsao SW: Phenotypic alterations induced by the Hong Kong-prevalent Epstein-Barr virusencoded LMP1 variant (2117-LMP1) in nasopharyngeal epithelial cells. Int J Cancer 2004, 109(6):919-925.

6. Guo L, Tang M, Yang L, Xiao L, Bode AM, Li L, Dong Z, Cao Y: Epstein-Barr virus oncoprotein LMP1 mediates survivin upregulation by $\mathrm{p} 53$ contributing to $\mathrm{G} 1 / \mathrm{S}$ cell cycle progression in nasopharyngeal carcinoma. Int J Mol Med 2012, 29(4):574-580.

7. Floettmann JE, Ward K, Rickinson AB, Rowe M: Cytostatic effect of EpsteinBarr virus latent membrane protein-1 analyzed using tetracyclineregulated expression in B cell lines. Virology 1996, 223(1):29-40.

8. Hu LF, Chen F, Zheng X, Ernberg I, Cao SL, Christensson B, Klein G, Winberg $\mathrm{G}$ : Clonability and tumorigenicity of human epithelial cells expressing the EBV encoded membrane protein LMP1. Oncogene 1993, 8(6):1575-1583.

9. Hadhri-Guiga B, Khabir AM, Mokdad-Gargouri R, Ghorbel AM, Drira M, Daoud J, Frikha M, Jidi R, Gargouri A: Various 30 and 69 bp deletion variants of the Epstein-Barr virus LMP1 may arise by homologous recombination in nasopharyngeal carcinoma of Tunisian patients. Virus Res 2006, 115(1):24-30.

10. Knecht H, Bachmann E, Brousset P, Sandvej K, Nadal D, Bachmann F, Odermatt BF, Delsol G, Pallesen G: Deletions within the LMP1 oncogene of Epstein-Barr virus are clustered in Hodgkin's disease and identical to those observed in nasopharyngeal carcinoma. Blood 1993, 82(10):2937-2942.

11. Rothenberger S, Bachmann E, Berger C, McQuain C, Odermatt BF, Knecht H: Natural 30 base pair and 69 base pair deletion variants of the LMP1 oncogene do stimulate NF-kappaB-mediated transcription. Oncogene 1997, 14(17):2123-2126.

12. Flavell K, Murray PG: Hodgkin's disease and the Epstein-Barr virus. Mol Pathol 2000, 53(5):262-269.

13. Dolcetti R, Boiocchi M, Gloghini A, Carbone A: Pathogenetic and histogenetic features of HIV-associated Hodgkin's disease. Eur I Cancer 2001, 37(10):1276-1287. 
14. Spina M, Carbone A, Gloghini A, Serraino D, Berretta M, Tirelli U: Hodgkin's Disease in Patients with HIV Infection. Adv Hematol 2011, 2011:402682.

15. Cader FZ, Vockerodt M, Bose S, Nagy E, Brundler MA, Kearns P, Murray PG: The EBV oncogene LMP1 protects lymphoma cells from cell death through the collagen-mediated activation of DDR1. Blood 2013, 122(26):4237-4245.

16. Gruss HJ, Pinto A, Duyster J, Poppema S, Herrmann F: Hodgkin's disease: a tumor with disturbed immunological pathways. Immunol Today 1997, 18(4):156-163

17. Skinnider BF, Mak TW: The role of cytokines in classical Hodgkin lymphoma. Blood 2002, 99(12):4283-4297.

18. Aldinucci D, Gloghini A, Pinto A, De Filippi R, Carbone A: The classical Hodgkin's lymphoma microenvironment and its role in promoting tumour growth and immune escape. J Pathol 2010, 221(3):248-263.

19. Maggio EM, Van Den Berg A, Visser L, Diepstra A, Kluiver J, Emmens R, Poppema S: Common and differential chemokine expression patterns in rs cells of NLP, EBV positive and negative classical Hodgkin lymphomas. Int J Cancer 2002, 99(5):665-672.

20. Diehl V, Kirchner HH, Burrichter H, Stein H, Fonatsch C, Gerdes J, Schaadt M, Heit W, Uchanska-Ziegler B, Ziegler A, Heintz F, Sueno K: Characteristics of Hodgkin's disease-derived cell lines. Cancer Treat Rep 1982, 66(4):615-632.

21. Kis LL, Nishikawa J, Takahara M, Nagy N, Matskova L, Takada K, Elmberger PG, Ohlsson A, Klein G, Klein E: In vitro EBV-infected subline of $\mathrm{KMH}$, derived from Hodgkin lymphoma, expresses only EBNA-1, while CD40 ligand and IL-4 induce LMP-1 but not EBNA-2. Int J Cancer 2005, 113(6):937-945

22. Baumforth KR, Flavell JR, Reynolds GM, Davies G, Pettit TR, Wei W, Morgan S, Stankovic T, Kishi Y, Arai H, Nowakova M, Pratt G, Aoki J, Wakelam MJ, Young LS, Murray PG: Induction of autotaxin by the Epstein-Barr virus promotes the growth and survival of Hodgkin lymphoma cells. Blood 2005, 106(6):2138-2146.

23. Knecht H, McQuain C, Martin J, Rothenberger S, Drexler HG, Berger C, Bachmann E, Kittler EL, Odermatt BF, Quesenberry PJ: Expression of the LMP1 oncoprotein in the EBV negative Hodgkin's disease cell line L-428 is associated with Reed-Sternberg cell morphology. Oncogene 1996, 13(5):947-953.

24. Vockerodt M, Morgan SL, Kuo M, Wei W, Chukwuma MB, Arrand JR, Kube D, Gordon J, Young LS, Woodman CB, Murray PG: The Epstein-Barr virus oncoprotein, latent membrane protein-1, reprograms germinal centre $B$ cells towards a Hodgkin's Reed-Sternberg-like phenotype. J Pathol 2008, 216(1):83-92.

25. Faumont N, Trempat $P$, Brousset $P$, Delsol G, Meggetto F: In Hodgkin's disease Reed-Sternberg cells and normal B-lymphocytes are infected by related Epstein-Barr virus strains. Virus Res 2004, 101(2):163-173.

26. Zuercher E, Butticaz C, Wyniger J, Martinez R, Battegay M, Boffi El Amari E, Dang T, Egger JF, Fehr J, Mueller-Garamvogyi E, Parini A, Schaefer SC, Schoeni-Affolter $F$, Thurnheer C, Tinguely M, Telenti A, Rothenberger S: Genetic Diversity of EBV-Encoded LMP1 in the Swiss HIV Cohort Study and Implication for NF-Kappab Activation. PLoS One 2012, 7(2):e32168.

27. Faumont N, Chanut A, Benard A, Cogne N, Delsol G, Feuillard J, Meggetto F: Comparative analysis of oncogenic properties and nuclear factor-kappaB activity of latent membrane protein 1 natural variants from Hodgkin's lymphoma's Reed-Sternberg cells and normal B-lymphocytes. Haematologica 2009, 94(3):355-363.

28. Sandvej K, Munch M, Hamilton-Dutoit S: Mutations in the Epstein-Barr virus latent membrane protein-1 (BNLF-1) gene in spontaneous lymphoblastoid cell lines: effect on in vitro transformation associated parameters and tumorigenicity in SCID and nude mice. Clin Mol Pathol 1996, 49(5):M290-M297.

29. Morris MA, Dawson CW, Wei W, O'Neil JD, Stewart SE, Jia J, Bell Al, Young LS, Arrand JR: Epstein-Barr virus-encoded LMP1 induces a hyperproliferative and inflammatory gene expression programme in cultured keratinocytes. J Gen Virol 2008, 89(Pt 11):2806-2820.

30. Eliopoulos AG, Gallagher NJ, Blake SM, Dawson CW, Young LS: Activation of the p38 mitogen-activated protein kinase pathway by Epstein-Barr virus-encoded latent membrane protein 1 coregulates interleukin- 6 and interleukin-8 production. J Biol Chem 1999, 274(23):16085-16096.

31. Nakagomi H, Dolcetti R, Bejarano MT, Pisa P, Kiessling R, Masucci MG: The Epstein-Barr virus latent membrane protein-1 (LMP1) induces interleukin-10 production in Burkitt lymphoma lines. Int J Cancer 1994, 57(2):240-244.
32. Tsai SC, Lin SJ, Lin CJ, Chou YC, Lin JH, Yeh TH, Chen MR, Huang LM, Lu MY, Huang YC, Chen HY, Tsai CH: Autocrine CCL3 and CCL4 induced by the oncoprotein LMP1 promote Epstein-Barr virus-triggered B cell proliferation. J Virol 2013, 87(16):9041-9052.

33. Najjar I, Baran-Marszak F, Le Clorennec C, Laguillier C, Schischmanoff O, Youlyouz-Marfak I, Schlee M, Bornkamm GW, Raphael M, Feuillard J, Fagard R: Latent membrane protein 1 regulates STAT1 through NF-kappaBdependent interferon secretion in Epstein-Barr virus-immortalized B cells. J Virol 2005, 79(8):4936-4943.

34. Khan G: Epstein-Barr virus, cytokines, and inflammation: a cocktail for the pathogenesis of Hodgkin's lymphoma? Exp Hematol 2006, 34(4):399-406.

35. Herbst H, Samol J, Foss HD, Raff T, Niedobitek G: Modulation of interleukin6 expression in Hodgkin and Reed-Sternberg cells by Epstein-Barr virus. J Pathol 1997, 182(3):299-306.

36. Marri PR, Hodge LS, Maurer MJ, Ziesmer SC, Slager SL, Habermann TM, Link BK, Cerhan JR, Novak AJ, Ansell SM: Prognostic significance of pretreatment serum cytokines in classical Hodgkin lymphoma. Clin Cancer Res 2013, 19(24):6812-6819.

37. Tao Y, Song X, Deng X, Xie D, Lee LM, Liu Y, Li W, Li L, Deng L, Wu Q, Gong J, Cao Y: Nuclear accumulation of epidermal growth factor receptor and acceleration of G1/S stage by Epstein-Barr-encoded oncoprotein latent membrane protein 1. Exp Cell Res 2005, 303(2):240-251.

38. Lam N, Sandberg ML, Sugden B: High physiological levels of LMP1 result in phosphorylation of elF2 alpha in Epstein-Barr virus-infected cells. $J$ Virol 2004, 78(4):1657-1664.

39. Brocqueville G, Ndour PA, Ouk TS, Le Goff A, De Witte C, Mougel A, Coll J, Fafeur V, Le Bourhis X, Adriaenssens E: LMP1-Induced Cell Death May Contribute to the Emergency of Its Oncogenic Property. PLOS One 2013, 8(4):e60743

40. Shao N, Chen LH, Ye RY, Lin Y, Wang SM: The depletion of interleukin-8 causes cell cycle arrest and increases the efficacy of docetaxel in breast cancer cells. Biochem Biophys Res Commun 2013, 431(3):535-541.

41. Higuchi R, Krummel B, Saiki RK: A general method of in vitro preparation and specific mutagenesis of DNA fragments: study of protein and DNA interactions. Nucleic Acids Res 1988, 16(15):7351-7367.

42. Dirmeier U, Neuhierl B, Kilger E, Reisbach G, Sandberg ML, Hammerschmidt W: Latent membrane protein 1 is critical for efficient growth transformation of human B cells by epstein-barr virus. Cancer Res 2003, 63(11):2982-2989.

43. Le Clorennec C, Le Clorennec C, Ouk TS, Youlyouz-Marfak I, Panteix S, Martin CC, Rastelli J, Adriaenssens E, Zimber-Strobl U, Coll J, Feuillard J, Jayat-Vignoles C: Molecular basis of cytotoxicity of Epstein-Barr virus (EBV) latent membrane protein 1 (LMP1) in EBV latency III B cells: LMP1 induces type II ligand-independent autoactivation of CD95/Fas with caspase 8-mediated apoptosis. J Virol 2008, 82(13):6721-6733.

\section{doi:10.1186/1743-422X-11-94}

Cite this article as: Sueur et al:: Difference in cytokine production and cell cycle progression induced by Epstein-Barr virus Lmp1 deletion variants in Kmh2, a Hodgkin lymphoma cell line. Virology Journal 2014 11:94

\section{Submit your next manuscript to BioMed Central and take full advantage of:}

- Convenient online submission

- Thorough peer review

- No space constraints or color figure charges

- Immediate publication on acceptance

- Inclusion in PubMed, CAS, Scopus and Google Scholar

- Research which is freely available for redistribution 